\title{
Control of Micellar Size and Critical Micelle Concentration for "Nonamphiphilic" Poly(vinyl phenol)-block-Polystyrene Diblock Copolymers
}

\author{
Eri YosHIDA \\ Department of Polymer Science and Engineering, Kyoto Institute of Technology, \\ Goshokaido-cho, Matsugasaki, Sakyo, Kyoto 606-8585, Japan
}

(Received July 11, 2003; Accepted October 2, 2003)

\begin{abstract}
Control of micellar size and cmc was studied for nonamphiphilic poly(vinyl phenol)-block-polystyrene diblock copolymers (PVPh- $b$-PSt) in the micellization by 1,4-butanediamine (BDA). The micellization was explored for the copolymers with $\mathrm{Mn}(\mathrm{PSt}$ blocks $)=20 \mathrm{~K}, 35 \mathrm{~K}, 75 \mathrm{~K}$, and $125 \mathrm{~K}$, holding the PVPh block length constant $(\mathrm{Mn}(\mathrm{PVPh}$ blocks $)=10 \mathrm{~K}$ ), in order to investigate effect of the PSt block length on the size of micelles. Dynamic light scattering demonstrated that the copolymers with longer PSt blocks formed larger micelles, although the copolymers had a slight difference in the unimer size. The copolymers had the transition from the unimers to the micelles at the same BDA concentration, indicating that the cmc of the copolymers was independent of the PSt block length. The PVPh block length had effects not only on the micellar size but also on the cmc. The copolymers with longer PVPh blocks showed the transition at lower BDA concentration. When the copolymers had almost the same unit ratios of VPh to St, the copolymer with larger molecular weight formed larger micelles at lower BDA concentration. The size of micelles and the $\mathrm{cmc}$ were also manipulated by the mixed ratio of the copolymers with different block length.

KEY WORDS Poly(vinyl phenol)-block-Polystyrene (PVPh- $b$-PSt) / Nonamphiphilic Diblock Copolymers / Micelles / Unimers / Hydrodynamic Radius / Critical Micelle Concentration / Block Length /
\end{abstract}

Surfactants are of great importance in various fields of coloring, ${ }^{1,2}$ coating, ${ }^{3-5}$ adhesion, ${ }^{6,7}$ water purification, ${ }^{8}$ paper manufacturing,,${ }^{9,10}$ food processing, ${ }^{11}$ and drug delivery. ${ }^{12,13}$ Polymeric and oligomeric surfactants are superior to monomeric surfactants in forming large size of aggregates ${ }^{14,15}$ and in stabilizing the shapes against changes in the circumstances. ${ }^{16,17}$ The polymeric surfactants have such benign nature environmentally so that those have been utilized as foodadditives, ${ }^{18,19}$ dispersing agents for cosmetics, ${ }^{20,21}$ and drug carriers. ${ }^{22,23}$ The surfactants are usually amphiphilic copolymers such as block, graft, and random copolymers. The block length of hydrophobic and hydrophilic moieties in the amphiphilic copolymers is an important factor to determine the physical properties of micelles such as the size of micelles, the critical micelle concentration, and the critical micelle temperature. ${ }^{16,24}$ Accordingly, the block length and ratios always need to be taken into consideration in designing the amphiphilic copolymers.

Recently, we have found the micelle formation from "nonamphiphilic" block copolymers consisting entirely of solvent-soluble blocks. ${ }^{25}$ The copolymers themselves show no self-assembly into micelles, however, those form micelles through aggregation of part of the structures by interacting with additives. The nonamphiphilic copolymers should create micelles in a great variety because the molecular design of the micelles can be allowed through designing the copolymers and the additives. We attained the micelle formation for a nonamphiphilic poly(vinylphenol)-block-polystyrene diblock copolymer (PVPh- $b$-PSt) through hydrogen bond cross-linking between the PVPh blocks by $\alpha, \omega$ diamine. ${ }^{26}$ In this micellization, an excess of the diamine molecules over the vinyl phenol units was considered to form hydrogen bond networks in the cores of the micelles. In fact, the PVPh- $b$-PSt diblock copolymer at lower copolymer concentration needed more diamine to form micelles. We obtained the interesting result that the critical micelle concentration $(\mathrm{cmc})$ was determined by a diamine concentration at a constant copolymer concentration, and also by a copolymer concentration at a constant diamine concentration. The nonamphiphilic diblock copolymer produced crew-cut micelles with long core blocks and short corona chains without use of selective solvents. The effect of block length on the micellization has remained an intriguing matter for the PVPh- $b$-PSt diblock copolymers, although it is well known for amphiphilic diblock copolymers. ${ }^{16}$ This is because in the nonamphiphilic copolymer micelles the polymer blocks forming the cores are rather extending than shrinking, based on the fact that the micelles are formed by hydrogen bond crosslinking. This paper describes effects of the block length on the micellar size and the $\mathrm{cmc}$ in the micellization of PVPh- $b$-PSt by 1,4-butanediamine (BDA). The prepa- 
ration of mixed micelles from the PVPh- $b$-PSt copolymers with different block length is also described.

\section{EXPERIMENTAL}

\section{Measurements}

Dynamic light scattering experiments were performed at $20^{\circ} \mathrm{C}$ at an angle of $90^{\circ}$, with a Photal Otsuka Electronics DLS-7000 super dynamic light scattering spectrometer equipped with LS-71 control unit, an LS72 pump controller, and an argon ion laser operating at $\lambda=488 \mathrm{~nm}$.

\section{Materials}

The PVPh- $b$-PSt diblock copolymers were prepared as reported previously. ${ }^{25} \mathrm{BDA}$ was distilled over calcium hydride. 1,4-Dioxane was purified by refluxing on sodium for several hours, and was distilled over sodium.

\section{Light Scattering Measurements for a Mixture of the PVPh-b-PSt Copolymers}

The copolymers with Mn(PVPh- $b$-PSt $)=10 \mathrm{~K}-b-$ $20 \mathrm{~K}(5 \mathrm{mg})$ and $10 \mathrm{~K}-b-125 \mathrm{~K}(5 \mathrm{mg})$ were dissolved in 1,4-dioxane $(3.1 \mathrm{~mL})$ and using a syringe, the resulting solution was injected through a microporous filter into a cell. The solution was subjected to light scattering measurement at $20^{\circ} \mathrm{C}$. After the measurement, $6 \mu \mathrm{L}$ of BDA solution (BDA, $174 \mu \mathrm{L}, 1.73 \mathrm{mmol}$ ) in 1,4dioxane $(2 \mathrm{~mL})$ was added to the copolymer solution in the cell, and the mixture was shaken vigorously. The solution was allowed to stand at $20^{\circ} \mathrm{C}$ for $5 \mathrm{~min}$, and then subjected to light scattering measurement again. This procedure was repeated until distribution based on the hydrodynamic radius of the unimers was not observed as determined by non-negatively constrained least squares (NNLS) analysis. ${ }^{27}$ Hydrodynamic radius of the copolymer was determined by cumulant analysis.

\section{RESULTS AND DISCUSSION}

The micellization of the PVPh- $b$-PSt diblock copolymers by BDA was explored holding the PVPh block length constant $(\mathrm{Mn}(\mathrm{PVPh}$ block $)=10 \mathrm{~K})$, in order to investigate effect of the PSt block length on the size of micelles. Figure 1 shows the variation in the hydrodynamic radius of the copolymers versus the BDA concentration through the micellization for four copolymers with $\mathrm{Mn}$ (PSt block) $=20 \mathrm{~K}, 35 \mathrm{~K}, 70 \mathrm{~K}$, and $125 \mathrm{~K}$. The DLS was performed at $20^{\circ} \mathrm{C}$ and an angle $\theta=90^{\circ}$ for a copolymer concentration $=3.23 \mathrm{~g} \mathrm{~L}^{-1}$. The copolymers remained as unimers in the absence of BDA. The hydrodynamic radius of the unimers in-

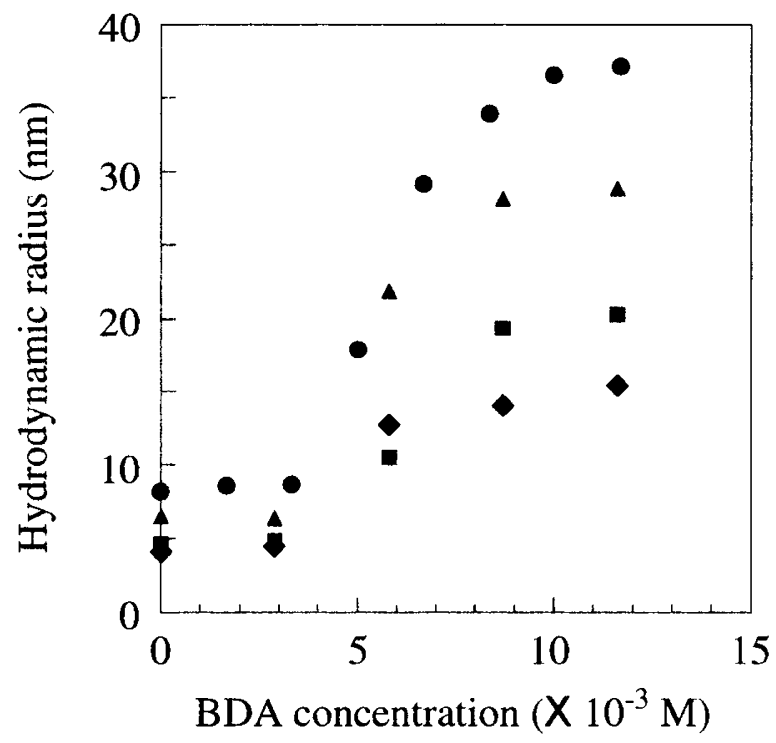

Figure 1. Variation of hydrodynamic radius over BDA concentration at a copolymer concentration $=3.23 \mathrm{~g} \mathrm{~L}^{-1}$ for the copolymers with $\mathrm{Mn}($ PSt blocks $)=125 \mathrm{~K}(\bullet), 70 \mathrm{~K}(\boldsymbol{\bullet}), 35 \mathrm{~K}(\bullet)$, and $20 \mathrm{~K}(\bullet) . \mathrm{Mn}(\mathrm{PVPh}$ blocks $)=10 \mathrm{~K}$.

creased as the molecular weight of the PSt blocks increased, however, the difference in the unimer size was small among the copolymers. The hydrodynamic radii showed jumps around $5 \times 10^{-3} \mathrm{M}$ of the BDA concentration. At the BDA concentration of $6 \times 10^{-3} \mathrm{M}$, the molar ratios of BDA to the $\mathrm{VPh}$ unit ratio were 0.7 , $1.0,1.8$, and 3.1 for the $20 \mathrm{~K}, 35 \mathrm{~K}, 70 \mathrm{~K}$, and $125 \mathrm{~K}$ samples, respectively. This indicates that the transition from the unimers to the micelles occurred at almost the same BDA concentration, in spite of the fact that the individual copolymers contained different molar fraction of the VPh units in the copolymer solution. The copolymer with longer PSt blocks contains smaller molar fraction of the VPh units, since the copolymer concentration is constant $\left([\right.$ copolymer $\left.]=3.23 \mathrm{~g} \mathrm{~L}^{-1}\right)$. Consequently, the cmc of the copolymers was determined by a BDA concentration in the solution rather than by the BDA/VPh ratio. The result that the copolymer with longer PSt blocks needed more BDA/VPh ratio to form micelles is understandable when it is taken into account that the copolymer at lower copolymer concentration needed more BDA. ${ }^{26}$ The occurrence of the transition at the same BDA concentration implies that the PSt block length has negligible effect on the cmc. After the jumps of the hydrodynamic radii, those gradually increased with an increase in the BDA concentration. BDA was added to the copolymer solutions until the micellization was completed. The complete micellization was confirmed by the NNLS analysis, where no intensity distribution of the hydrodynamic radius based on the unimers was observed. The hydrodynamic radius at the micellization completed is larger as the PSt 


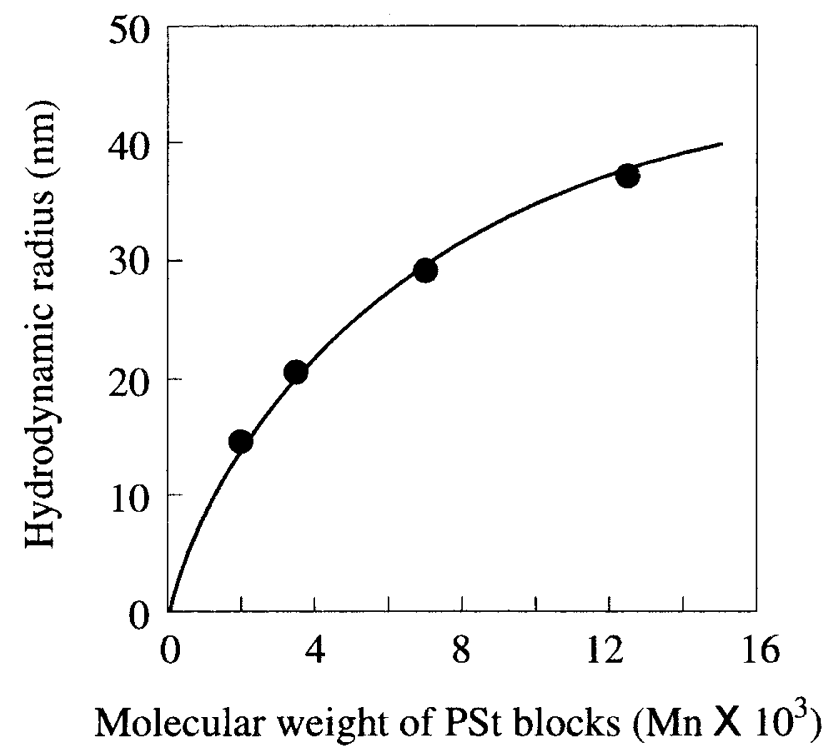

Figure 2. Relationship between the molecular weight of the PSt blocks and the hydrodynamic radius at the micellization completed. $\mathrm{Mn}(\mathrm{PVPh}$ blocks $)=10 \mathrm{~K}$.

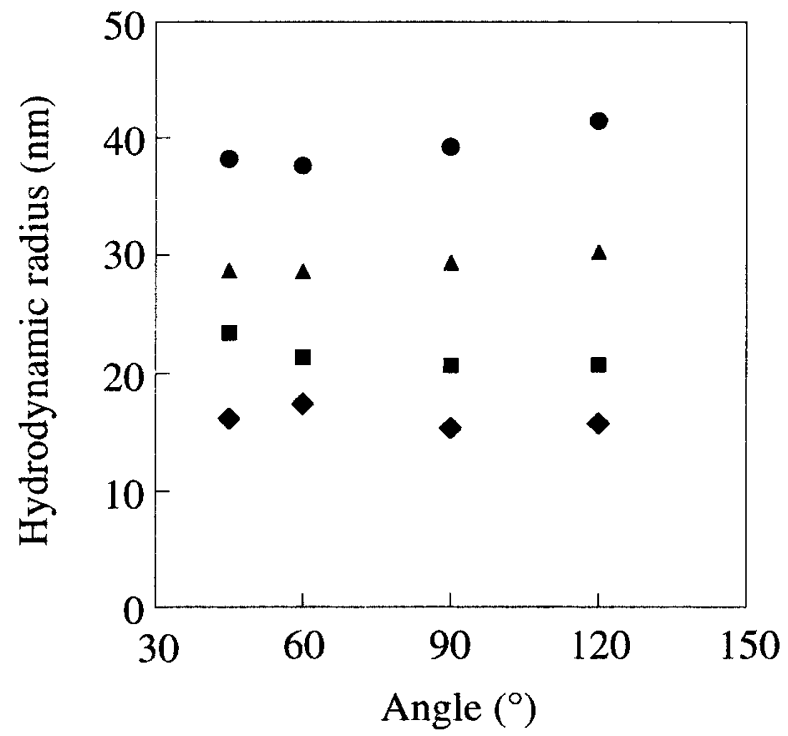

Figure 3. Plots of hydrodynamic radius of the micelles versus angle for the copolymers with $\mathrm{Mn}(\mathrm{PSt}$ blocks $)=125 \mathrm{~K}(\bullet), 70 \mathrm{~K}$ $(\boldsymbol{\Lambda}), 35 \mathrm{~K}(\bullet)$, and $20 \mathrm{~K}(\bullet) . \mathrm{Mn}(\mathrm{PVPh}$ blocks $)=10 \mathrm{~K}$. [PVPh- $b-$ PSt $]=3.23 \mathrm{~g} \mathrm{~L}^{-1}$.

block is longer, indicating that the micellar size is dependent on the length of the PSt blocks forming the coronas of the micelles. Figure 2 shows the relationship between the molecular weight of the PSt blocks and the hydrodynamic radius of the copolymers at the complete micellization. The hydrodynamic radius of the micelles is proportional to the molecular weight of the PSt blocks, suggesting that the size of micelles is determined primarily by the PSt block length. In addition, the size of micelles was independent of the angle (Figure 3).

The effect of the PVPh block length on the mi-

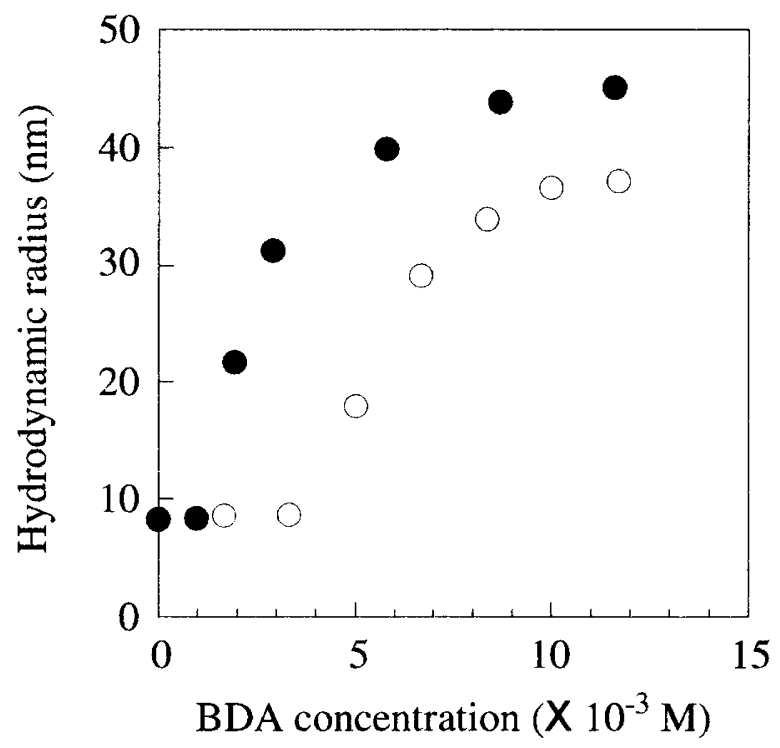

Figure 4. Variation of hydrodynamic radius over BDA concentration for the $20 \mathrm{~K}-b-150 \mathrm{~K}(\bullet)$ and $10 \mathrm{~K}-b-125 \mathrm{~K}(\mathrm{O})$ copolymers. $[\mathrm{PVPh}-b-\mathrm{PSt}]=3.23 \mathrm{~g} \mathrm{~L}^{-1}$.

cellization was also examined using the PVPh- $b$-PSt copolymers with the similar molecular weights of the PSt blocks. Figure 4 shows the variation in the hydrodynamic radius in the micellization of the copolymers with $\mathrm{Mn}(\mathrm{PVPh}-b-\mathrm{PSt})=10 \mathrm{~K}-b-125 \mathrm{~K}$ and $20 \mathrm{~K}-$ $b-150 \mathrm{~K}$. The $20 \mathrm{~K}-b-150 \mathrm{~K}$ copolymer formed larger micelles than the $10 \mathrm{~K}-b-125 \mathrm{~K}$ copolymer, and the hydrodynamic radius of the micelles for the $20 \mathrm{~K}-b$ $150 \mathrm{~K}$ was estimated to be $45 \mathrm{~nm}$ by dynamic light scattering. There is no plot at $150 \mathrm{~K}$ of the molecular weight of the PSt blocks in Figure 2, however, the curve gives $c a .40 \mathrm{~nm}$ of the hydrodynamic radius at $\mathrm{Mn}(\mathrm{PSt}$ block $)=150 \mathrm{~K}$. The hydrodynamic radius of the micelles for the $20 \mathrm{~K}-b-150 \mathrm{~K}$ copolymer is still larger than that given by the curve at $\mathrm{Mn}$ (PSt block) = $150 \mathrm{~K}$. Accordingly, the micellar size is dependent not only on the PSt blocks but also on that of the PVPh blocks. The hydrodynamic radius for the $20 \mathrm{~K}-b-150 \mathrm{~K}$ copolymer was shifted to a lower side of the BDA concentration throughout the micellization, indicating that the copolymer needed less BDA to form micelles than the $10 \mathrm{~K}-b-125 \mathrm{~K}$ copolymer. An increase in the molecular weight of the PVPh blocks causes an increase in the cross-linking points of the hydrogen bonding with BDA, resulting in promoting the micellization by strong hydrogen bonding. It can be deduced that the $\mathrm{cmc}$ is manipulated by the molecular weight of the PVPh blocks.

The micellization of the PVPh- $b$-PSt copolymers with different molecular weights and the same $\mathrm{VPh} / \mathrm{St}$ unit ratios was investigated. Figure 5 shows the variation in the hydrodynamic radius in the micellization for the copolymers with $\mathrm{Mn}(\mathrm{PVPh}-b-\mathrm{PSt})=10 \mathrm{~K}-b-$ 


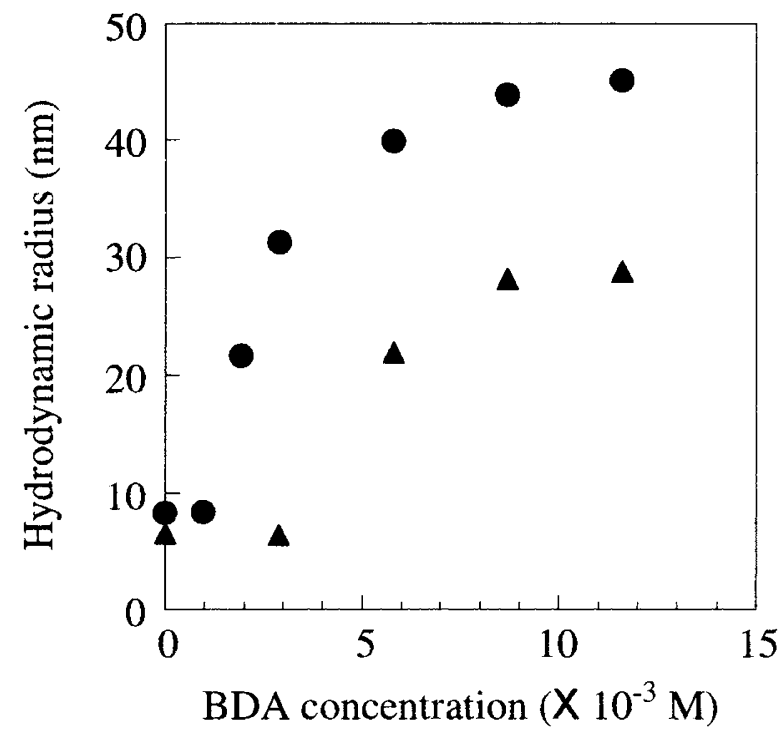

Figure 5. Variation of hydrodynamic radius over BDA concentration for the $20 \mathrm{~K}-b-150 \mathrm{~K}(\bullet)$ and $10 \mathrm{~K}-b-70 \mathrm{~K}(\mathbf{\Delta})$ copolymers. $[\mathrm{PVPh}-b$-PSt $]=3.23 \mathrm{~g} \mathrm{~L}^{-1}$.

$70 \mathrm{~K}$ and $20 \mathrm{~K}-b-150 \mathrm{~K}$. The micellization of the $20 \mathrm{~K}-$ $b-150 \mathrm{~K}$ copolymer occurred at a lower BDA concentration to produce the larger size of micelles compared with the $10 \mathrm{~K}-b-70 \mathrm{~K}$ copolymer. This indicates that the $20 \mathrm{~K}-b-150 \mathrm{~K}$ copolymer is much easier to form micelles than the $10 \mathrm{~K}-b-70 \mathrm{~K}$ copolymer, although there is a slight difference in the unit ratio of $\mathrm{VPh}$ to St between the $20 \mathrm{~K}-b-150 \mathrm{~K}$ and $10 \mathrm{~K}-b-70 \mathrm{~K}$ copolymers. Consequently, the size of micelles is determined by the molecular weights of both the PSt and PVPh blocks, while the cmc is mainly by that of the PVPh blocks.

The micellar size and the cmc may be controlled not only by the block length but also by a mixed ratio of the copolymers. The copolymers with $\mathrm{Mn}(\mathrm{PVPh}-$ $b$-PSt $)=10 \mathrm{~K}-b-20 \mathrm{~K}$ and $10 \mathrm{~K}-b-125 \mathrm{~K}$ were used in this study. Figure 6 shows the intensity distribution of the hydrodynamic radius for the mixture of the copolymers at 50/50 (wt/wt) of the mixed ratio. The distributions of scattering intensity versus hydrodynamic radius were determined by the NNLS analysis. The copolymers remain as unimers at the BDA concentration of $1.67 \times 10^{-3} \mathrm{M}$. The intensity distributions of the unimers originating from the respective copolymers could not be distinguished in the NNLS analysis so that one distribution was observed around $7 \mathrm{~nm}$ of the hydrodynamic radius. At $5.02 \times 10^{-3} \mathrm{M}$ of the BDA concentration, the distribution attributed to the micelles was seen around $30 \mathrm{~nm}$, in addition to the distribution of the unimers. The intensity of the distribution based on the unimers decreased at $6.70 \times 10^{-3} \mathrm{M}$. Finally, one distribution of the micelles was observed at $8.37 \times 10^{-3} \mathrm{M}$. The NNLS analysis of the micelles prepared separately from the $10 \mathrm{~K}-b-20 \mathrm{~K}$ and $10 \mathrm{~K}$ -

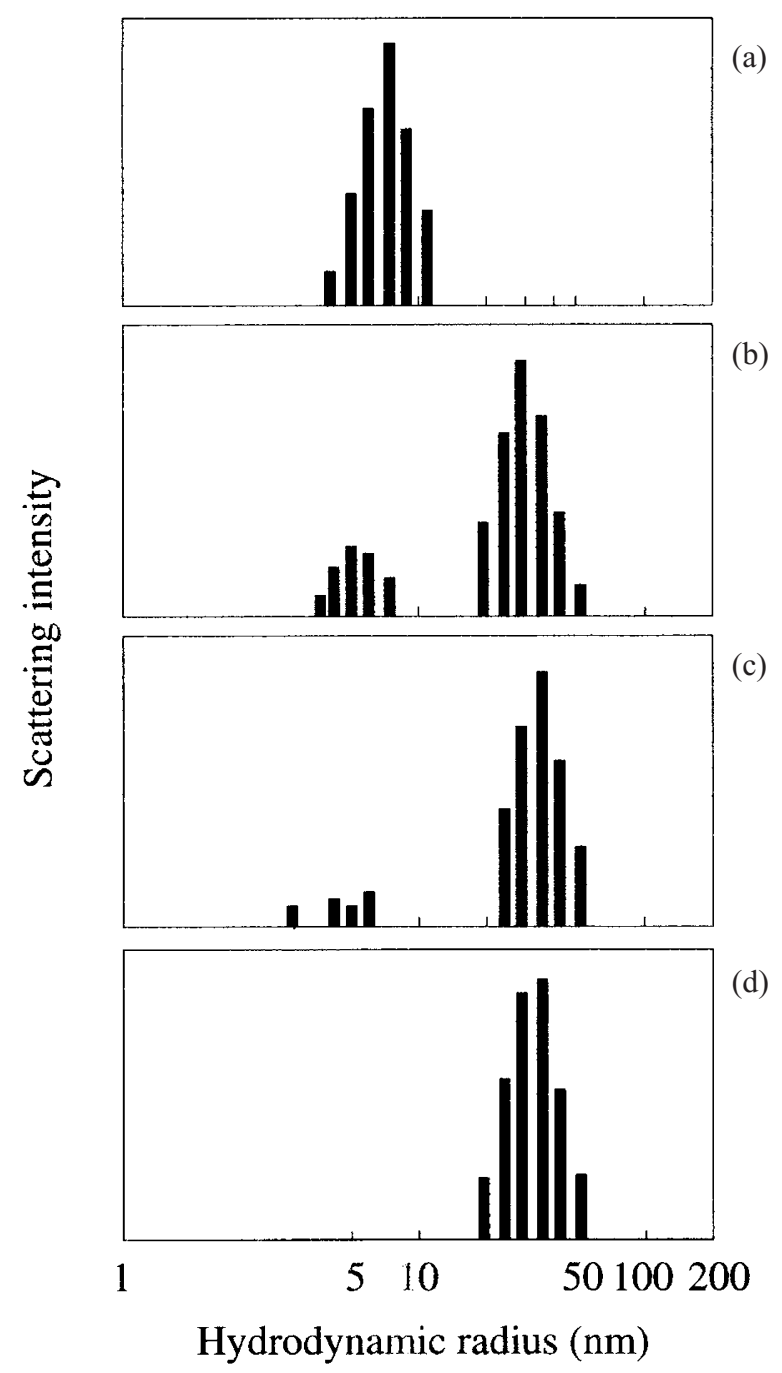

Figure 6. Intensity distribution of the hydrodynamic radius for the mixture of the $10 \mathrm{~K}-b-20 \mathrm{~K}$ and $10 \mathrm{~K}-b-125 \mathrm{~K}$ copolymers at the mixed ratio of 50/50 (wt/wt) for BDA concentrations $=1.67 \times 10^{-3}$ (a), $5.02 \times 10^{-3}$ (b), $6.70 \times 10^{-3}(\mathrm{c})$, and $8.37 \times 10^{-3} \mathrm{M}(\mathrm{d})$.

$b-125 \mathrm{~K}$ copolymers demonstrated that the mixture of the copolymers formed the mixed micelles. Figure 7 shows the intensity distribution of the different micelles produced from the $10 \mathrm{~K}-b-20 \mathrm{~K}$ copolymer, the $10 \mathrm{~K}$ $b-125 \mathrm{~K}$, and the mixture. The distribution of the micelles from the $10 \mathrm{~K}-b-20 \mathrm{~K}$ copolymer was observed around $15 \mathrm{~nm}$ of the hydrodynamic radius, while that of the $10 \mathrm{~K}-b-125 \mathrm{~K}$ micelles was seen around $40 \mathrm{~nm}$. The distribution of the micelles for the mixture was located between those of the micelles for the $10 \mathrm{~K}-b-20 \mathrm{~K}$ and $10 \mathrm{~K}-b-125 \mathrm{~K}$ copolymers. This indicates that the micelles obtained by the mixing of the copolymers are not a mixture of the micelles formed separately from the copolymers (Scheme 1).

Figure 8 shows the variation in the hydrodynamic radius through the micellization of the mixtures with the different mixed ratios. The mixtures showed jumps of the hydrodynamic radius at almost the same BDA concentration, indicating that the BDA concentration at the 


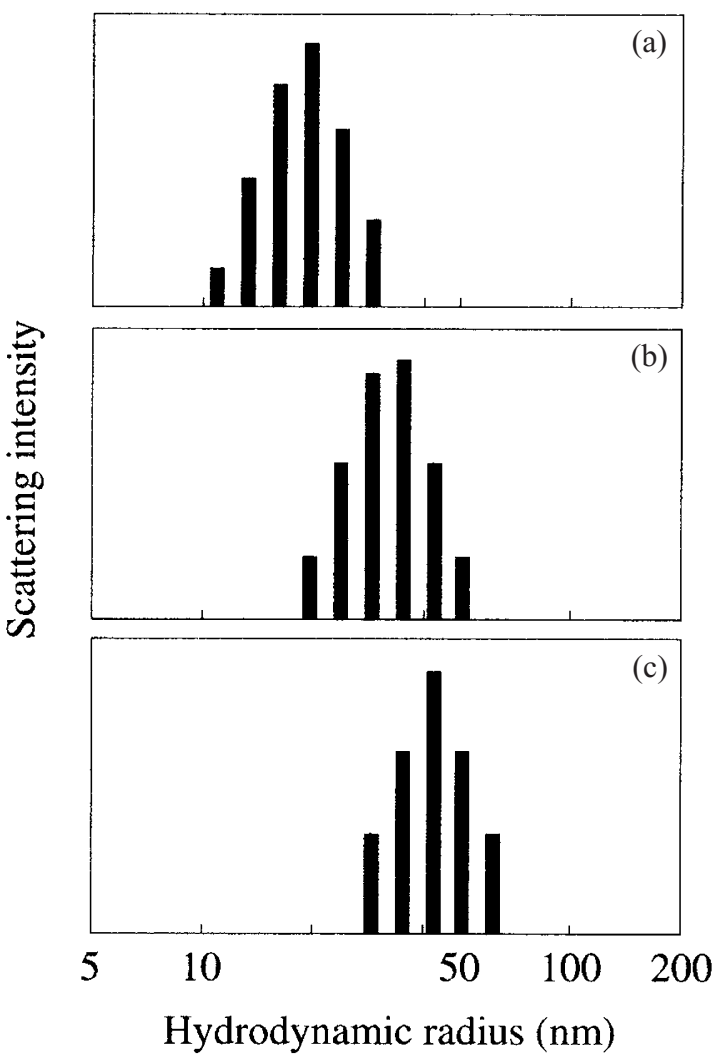

Figure 7. Intensity distribution of the hydrodynamic radius of the micelles produced from the $10 \mathrm{~K}-b-20 \mathrm{~K}$ copolymer (a), the mixture (b), and the $10 \mathrm{~K}-b-125 \mathrm{~K}$ copolymer (c).
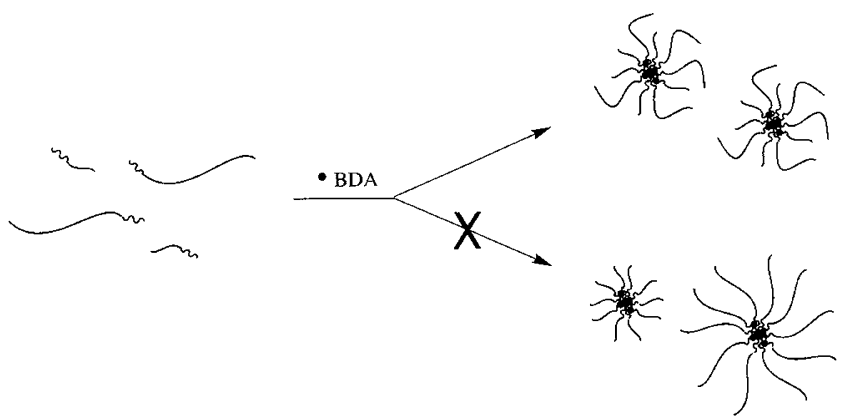

Scheme 1.

transition was independent of the mixed ratio. The hydrodynamic radius of the unimers for the mixtures was also independent of the mixed ratio. However, there is a remarkable difference in the hydrodynamic radius after the transition among the mixtures. The hydrodynamic radius of the mixture increased with an increase in the proportion of the $10 \mathrm{~K}-b-125 \mathrm{~K}$ copolymer in the mixture. As can be seen in Figure 9, the hydrodynamic radius of the mixture at the complete micellization was directly proportional to the proportion of the $10 \mathrm{~K}-b$ $125 \mathrm{~K}$ copolymer in the mixture. This indicates that the micellar size is controlled by the mixed ratio of the copolymers at a constant molecular weight of the PVPh blocks. It was found that the size of the mixed micelles was independent of the angle as was that of the single

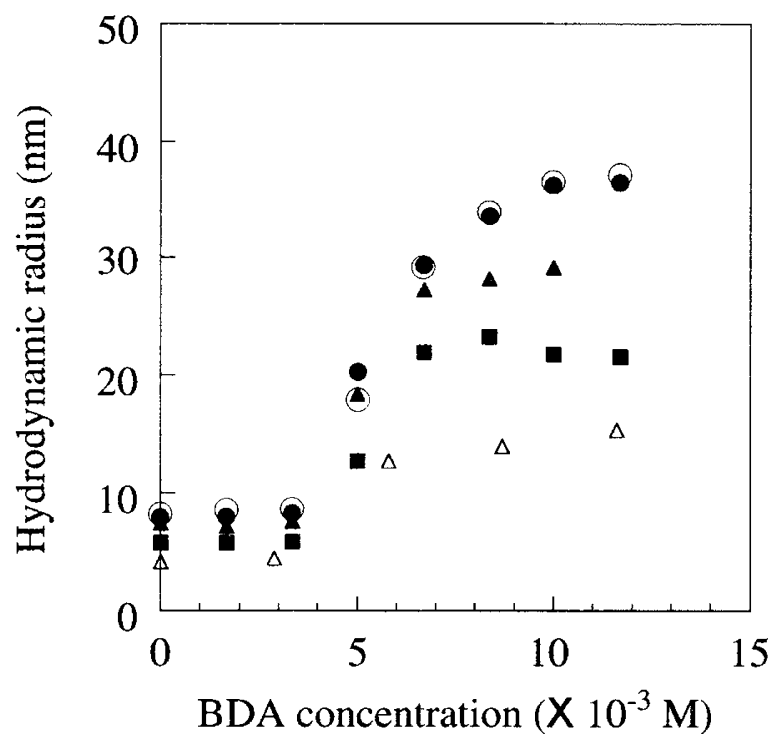

Figure 8. Variation of hydrodynamic radius over BDA concentration for the mixtures of the $10 \mathrm{~K}-b-125 \mathrm{~K}$ and $10 \mathrm{~K}-b-20 \mathrm{~K}$ copolymers at the mixed ratios, $10 \mathrm{~K}-b-125 \mathrm{~K} / 10 \mathrm{~K}-b-20 \mathrm{~K}=100 / 0$ $(\circ), 80 / 20(\bullet), 50 / 50(\Delta), 20 / 80(\bullet)$, and 0/100 ( $\triangle)(\mathrm{wt} / \mathrm{wt})$.

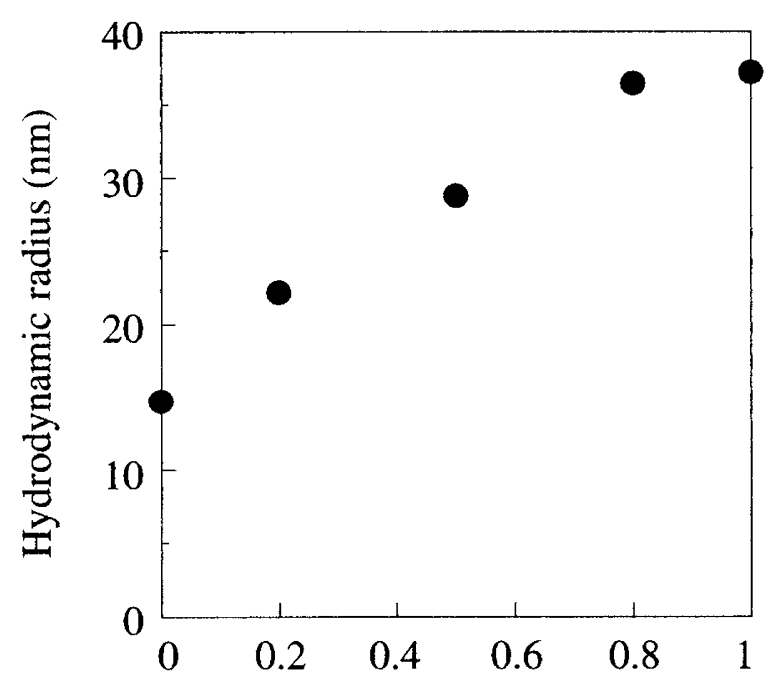

Proportion of the $10 \mathrm{~K}-b-125 \mathrm{~K}$ copolymer

Figure 9. Relationship between the proportion of the $10 \mathrm{~K}-b$ $125 \mathrm{~K}$ copolymer in the mixtures and the hydrodynamic radius of the mixtures at the micellization completed.

micelles (Figure 10).

The mixing of the copolymers with the same block length of PSt but the different length of PVPh has the potential to manipulate the cmc of the copolymers. Figure 11 shows the variation in the hydrodynamic radius for the mixture of the $10 \mathrm{~K}-b-125 \mathrm{~K}$ and $20 \mathrm{~K}-b-150 \mathrm{~K}$ copolymers at 50/50 (wt/wt) of the mixed ratio. The hydrodynamic radius of the mixture was observed between those of the respective copolymers during the transition, although it was equal to the size of the $20 \mathrm{~K}$ $b-150 \mathrm{~K}$ copolymer at the complete micellization. This suggests that the cmc can be controlled by the mixed 


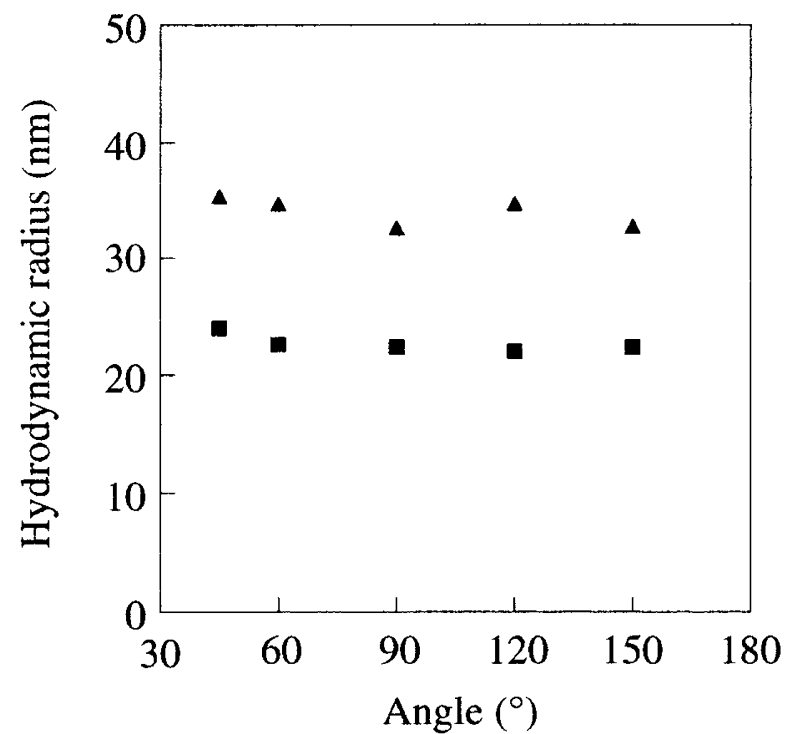

Figure 10. Plots of hydrodynamic radius of the mixed micelles versus angle. The mixed micelles prepared from the $10 \mathrm{~K}$ $b-125 \mathrm{~K}$ and $10 \mathrm{~K}-b-20 \mathrm{~K}$ copolymers at the mixed ratios, $10 \mathrm{~K}-b-$ $125 \mathrm{~K} / 10 \mathrm{~K}-b-20 \mathrm{~K}=50 / 50(\boldsymbol{\Lambda})$ and 20/80 (-) (wt/wt).

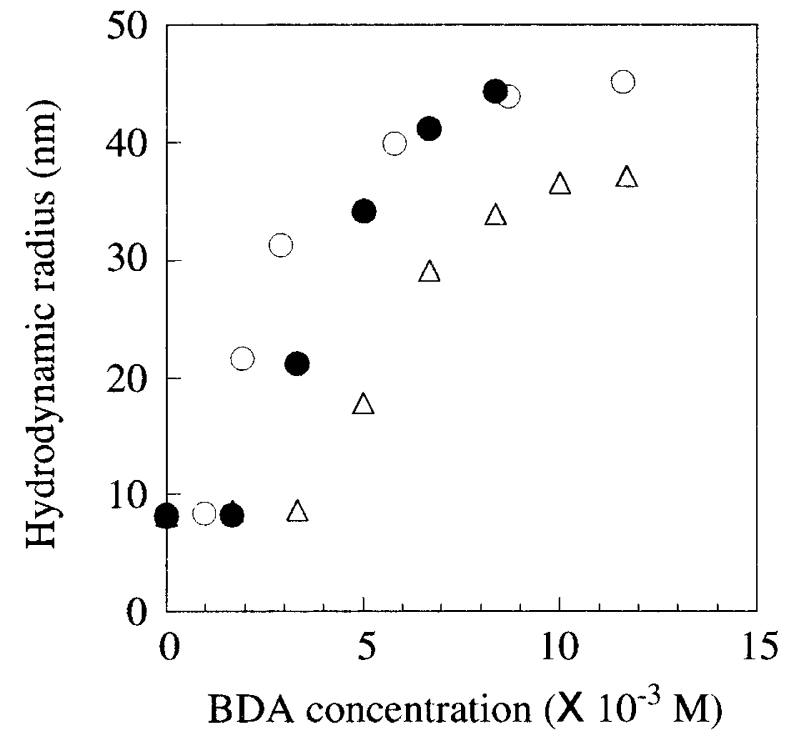

Figure 11. Variation of hydrodynamic radius over BDA concentration for the $20 \mathrm{~K}-b-150 \mathrm{~K}(\mathrm{O})$ and $10 \mathrm{~K}-b-125 \mathrm{~K}$ copolymers $(\triangle)$, and the mixture $(\bullet)$ at the mixed ratio of $50 / 50(\mathrm{wt} / \mathrm{wt})$.

ratio of the copolymers.

\section{CONCLUSIONS}

The effect of the block length on the micellar size and the cmc was investigated in the micellization of the PVPh- $b$-PSt diblock copolymers by BDA. Dynamic light scattering demonstrated that the copolymers with longer PSt blocks formed larger micelles at a constant PVPh block length. The copolymers had the transition from the unimers to the micelles at the same BDA concentration, independent of the PSt block length. The PSt block length had effect on the micellar size, but had negligible effect on the cmc. The PVPh block length had effects not only on the micellar size but also on the cmc. The copolymer with longer PVPh block length needed less BDA to form micelles, owing to an increase in the cross-linking points of the hydrogen bonding on the PVPh blocks. When the copolymers had almost the same unit ratios of $\mathrm{VPh}$ to St, the copolymer with larger molecular weight formed larger micelles at lower BDA concentration. This indicates that the copolymer with longer block length is easier to produce the micelles.

The size of micelles was also controlled by the mixed ratio of the copolymers with different PSt block length. For the mixture of the $10 \mathrm{~K}-b-20 \mathrm{~K}$ and $10 \mathrm{~K}-b-125 \mathrm{~K}$ copolymers, the size of the mixed micelles increased with an increase in the proportion of the $10 \mathrm{~K}-b-125 \mathrm{~K}$ copolymer in the mixture. Further, the mixing of the copolymers with the different PVPh block length had distinct effect on the $\mathrm{cmc}$, while that of the copolymers with the different PSt block length had negligible effect on it.

\section{REFERENCES}

1. D. Cohen, E. Hitchcock, and S. Pohl, Eur. Patent Appl., EP 640335 A2 (Mar. 1 1995).

2. H. Rajaraman, U.S. Patent US 6500896 B1 (Dec. 31 2002).

3. A. J. M. Knoef and H. Slingerland, Surf. Coat. Int., 75, 335 (1992).

4. T. Saji, K. Ebata, K. Sugawara, S. Liu, and K. Kobayashi, J. Am. Chem. Soc., 116, 6053 (1994).

5. A. R. Pitt, S. D. Morley, N. J. Burbidge, and E. L. Qiuckenden, Colloids Surf., A, 114, 321 (1996).

6. S. Prtyka, M. Lindheimer, and B. Faucompre, Colloids Surf., A, 76, 267 (1993).

7. J. Pakusch, M. Angel, A. Dragon, W. F. Beckerle, and H. Teichmann, Ger. Offen., DE 4426873 A1 (Feb. 1 1996).

8. J. W. Park and P. R. Jaffe, Environ. Sci. Technol., 27, 2559 (1993).

9. D. T. Nguyen C. J. Berzansky, and J. Charles, Can. Patent Appl., CA 2094632 (1993).

10. G. S. Hutcheson, U.S. Patent US 5292363 A (Mar. 8 1994).

11. A.-M. Sjoeberg, G. Wirtanen, and T. Mattila-Sandholm, Food Bioprod. Process., 73, 17 (1995).

12. K. A. Yoon and D. J. Burgess, J. Pharm. Pharmacol., 49, 478 (1997).

13. M. J. Lawrence, S. M. Lawrence, and D. J. Barlow, J. Pharm. Pharmacol. 49, 594 (1997).

14. N. A. Mazer, M. C. Carey, R. F. Kwasnick, and G. B. Benedek, Biochemistry, 18, 3064 (1979).

15. K. Schillen, W. Brown, and R. M. Johnsen, Macromolecules, 27, 2825 (1994).

16. E. Yoshida, S. Wells, and J. M. DeSimone, Kobunshi Ronbunshu, 58, 507 (2001).

17. O. Glatter, G. Scherf, K. Schillen, and W. Brown, Macromolecules, 27, 6046 (1994).

18. J. J. Lin and J. F. Knifton, J. Organomet. Chem., 417, 99 (1991). 
19. G. Dralle-Voss, G. Oetter, H. Wekel, and K. Oppenlaender, Ger. Offen. DE 19505100 A1 (Aug. 22 1996).

20. Y. C. Chiu and W. L. Yang, Colloids Surf., 63, 311 (1992).

21. C. Tondeur, H.-G. Riess, A. Meybeck, and J.-F. Tranchant, PCT Int. Appl. WO 9610045 A1 (Apr. 4 1996).

22. K. Kataoka, Drug Delivery Syst., 10, 363 (1995).

23. Y. Nagasaki, C. Carmen, M. Iijima, M. Kato, and K. Kataoka,
Controlled Release Bioact. Mater. $23 r d, 779$ (1996).

24. P. Linse and M. Malmsten, Macromolecules, 25, 5434 (1992).

25. E. Yoshida and S. Kunugi, J. Polym. Sci., Part A: Polym. Chem., 40, 3063 (2002).

26. E. Yoshida and S. Kunugi, Macromolecules, 35, 6665 (2002).

27. D. Morrison, E. F. Grabowski, and C. A. Herb, Langmuir, 1, 496 (1985). 